\title{
Chlorite control of correlations between strain and anisotropy of magnetic susceptibility
}

\author{
Bernard A. Housen and Ben A. van der Pluijm \\ Department of Geological Sciences, University of Michigan, 1006 C.C. Little Building, Ann Arbor, MI 48109 (U.S.A.)
}

(Received August 23, 1989; revision accepted October 10, 1989)

Housen, B.A. and van der Pluijm, B.A., 1990. Chlorite control of correlations between strain and anisotropy of magnetic susceptibility. Phys. Earth Planet. Inter., 61: 315-323.

\begin{abstract}
Anisotropy of magnetic susceptibility (AMS) has in the past been used as an indicator of finite strain; mathematical relationships between the measured AMS ellipsoid and the finite strain ellipsoid in slates are numerous. The Ordovician Martinsburg Formation at Lehigh Gap, Pennsylvania, provides a unique opportunity to test this correlation, as a complete shale-to-slate transition is preserved. Magnitudes of the principal susceptibility axes appear to reflect a strain gradient at this location. Apparent strain values derived from AMS, using equations from Rathore and Hrouda, have $X: Y: Z$ ratios from $2.79: 1.87: 0.19$ (shale) to $2.92: 0.82: 0.42$ (slate). The orientations of the susceptibility axes characterize two fabrics: (i) $k_{\text {in }} / k_{\max }$ planes at $20^{\circ}$ to bedding and (ii) $k_{\text {in }} / k_{\max }$ planes parallel to cleavage. Anisotropy of magnetic susceptibility fails to show any intermediate orientations of the principal susceptibility axes in the zone in which cleavage is developed. Comparison with phyllosilicate crystallographic orientations indicates that the AMS intermediate and maximum susceptibility axes are parallel to chlorite basal planes. Because chlorite reoriented via dissolution and new growth as cleavage developed in this location, and because models correlating AMS and strain instead assume that strain is reflected by the rotation of the magnetic susceptibility carriers, the apparent strain values calculated from AMS reflect only the degree of dissolution and neocrystallization in these rocks and not the finite strain.
\end{abstract}

\section{Introduction}

Anisotropy of magnetic susceptibility (AMS) has been widely used in the analysis of rock fabrics and strain. Analysis of AMS determines the combined susceptibility of paramagnetic, diamagnetic and ferrimagnetic minerals to an induction field in a sample. Studies in a variety of rock types have demonstrated that rock fabrics, such as bedding and cleavage, are reflected in the orientation of AMS principal axes (e.g. Kligfield et al., 1977; Borradaile, 1987; Rochette, 1987; Goldstein and Brown, 1988; Hirt et al., 1988; Hrouda et al., 1988). Combined studies of strain and AMS in rocks commonly attempt to correlate values of finite strain with the AMS ellipsoid, which is determined by the magnitudes (lengths) of the principal susceptibility axes. Various mathematical relationships between finite strain and AMS ellipsoids have been proposed (Owens, 1974; Wood et al., 1976; Rathore, 1979, 1988; Hrouda, 1980, 1987; Cogne and Perroud, 1988). Rathore (1979) and Hrouda (1987) related the ratios of principal susceptibility axes to March strains in slates using an exponential function based on the work by Owens (1974) and Wood et al. (1976). In contrast, Cogne and Perroud (1988) reported that the shapes and axial dimensions of the AMS ellipsoid and the strain ellipsoid were similar for a granite pluton. Experimental studies, however, have not demonstrated a direct correlation between strain and AMS; they reveal a consistent change in AMS fabric with increasing strain (Borradaile and Alford, 1987, 1988). In these experi- 


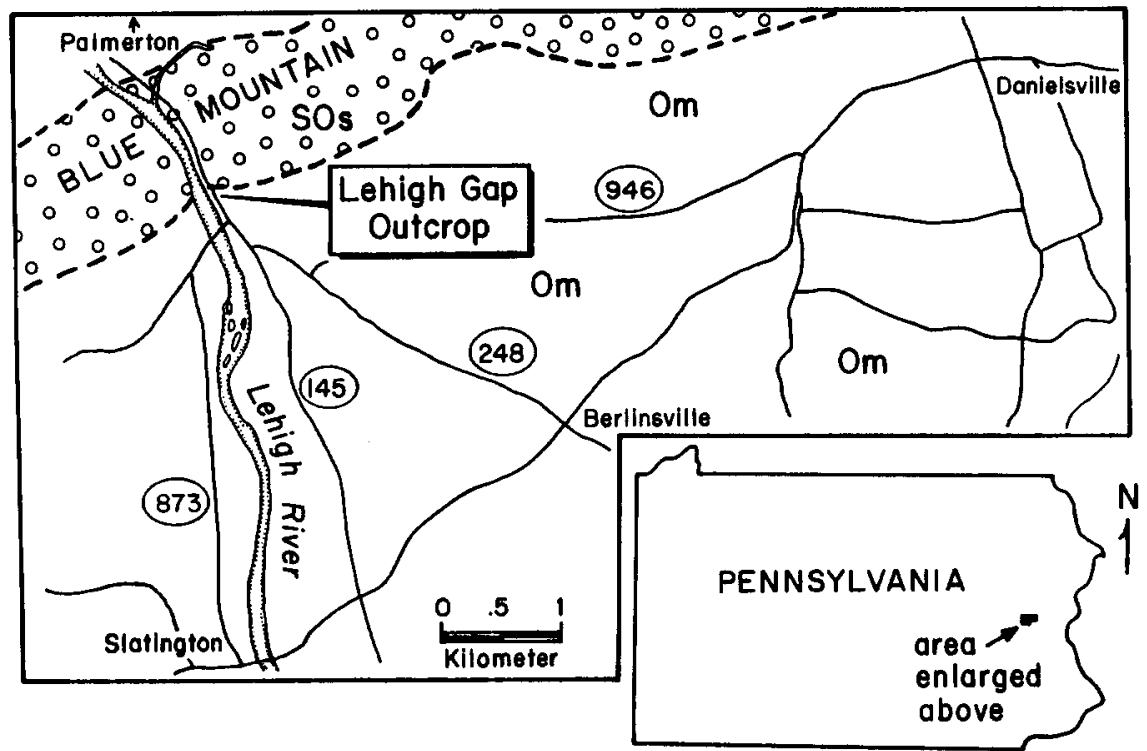

Fig. 1. Location map of study area. Highway numbers are shown for reference. The sample site at Lehigh Gap is located above the highway on an abandoned railroad grade. Om = Ordovician Martinsburg Formation, SOs = Ordovician-Silurian Shawangunk Formation.

ments, the correlation between AMS and rock fabric is imperfect however. The problem in correlating rock fabrics and strain with AMS may arise from differing contributions of diamagnetic (e.g. calcite), paramagnetic (e.g. chlorite) and ferrimagnetic (e.g. magnetite) minerals in a single sample. Borradaile (1988) noted that the ability of AMS to indicate rock fabric and strain may be improved when a single mineral determines the AMS.

This study examines the AMS of the Martinsburg Formation at Lehigh Water Gap, Pennsylvania (Fig. 1). The Martinsburg Formation in this location preserves the transition from an uncleaved shale at the contact with the overlying Shawangunk Formation to a well-cleaved slate over an interval of approximately $130 \mathrm{~m}$. The uncleaved shale displays moderate to well-developed bedding, which on average dips $40^{\circ} \mathrm{NNW}$. Incipient cleavage is first observed $\sim 75 \mathrm{~m}$ from the Shawangunk Formation contact, and cleavage development gradually increases in the interval of $75-120 \mathrm{~m}$ from the Shawangunk Formation contact. When fully developed, the slaty cleavage is pervasive and is consistently oriented perpendicular to the bedding plane, with an average dip of $60^{\circ}$ SSE.
The shale-to-slate transition at this outcrop has been studied extensively (Anonymous, 1885; McBride, 1962; Drake and Epstein, 1967; Epstein and Epstein, 1969; Holeywell and Tullis, 1975; Wintsch, 1978; Lee et al., 1986). Holeywell and Tullis (1975) and Wintsch (1978) considered this transition to be preserved in a pressure-shadow that was caused by the unconformably overlying Shawangunk Formation. Detailed microstructural study has indicated that dissolution and new growth of phyllosilicates characterizes the formation of cleavage in this outcrop (Lee et al., 1986).

Samples for AMS study were collected from 18 sites along this outcrop. The results of this study illustrate how changes in rock fabric and strain are manifested in magnetic fabrics when chlorite dominates the magnetic anisotropy.

\section{Sampling and analysis}

Oriented blocks comprising 18 sites were collected at regular intervals in a single, continuous outcrop from the Martinsburg-Shawangunk contact to a distance of $130 \mathrm{~m}$ (measured horizontally). Locations and site numbers were selected to 
facilitate comparison with the results of $\mathrm{X}$-ray texture goniometry data from Holeywell and Tullis (1975). Intact samples were difficult to extract from the outcrop owing to extensive fracturing. After the orientation was marked, blocks were covered with masking tape to prevent cracking of the sample prior to removal. The oriented blocks were then removed and wrapped completely in tape to prevent further breakage during transport. Once in the lab, the blocks were glued together, then coated with a thick layer of epoxy. Blocks were then mounted on a drill press and cores were drilled with a water-cooled drill. Each site provided three to five cores with a diameter of $2.5 \mathrm{~cm}$ and a length of $2.2 \mathrm{~cm}$. The AMS was measured with a Sapphire Instruments SI-2 susceptibility bridge with digital interface connected to a PC. Each analysis provides the orientations and magnitudes, as well as precision estimates, of the minimum, intermediate and maximum susceptibility axes (Stupavsky, 1984).

\section{Results}

Results of AMS analysis for the Martinsburg Formation display two distinct fabrics (Fig. 2), (i) a 'no-cleavage' fabric in which the minimum axis is generally $20^{\circ}$ steeper than the bedding pole, and (ii) a 'cleavage' fabric in which the minimum axis is at a high angle to the cleavage plane. For many of the cleaved samples the maximum axis is at the bedding-cleavage intersection. The AMS fabric, as seen in the orientation of the three AMS ellipsoid axes, changes abruptly from the 'nocleavage' fabric to the 'cleavage' fabric at a point $-75 \mathrm{~m}$ from the Shawangunk Formation contact. This abrupt change in AMS orientation is in marked contrast to the gradual development of cleavage reported over this interval (e.g. Holeywell and Tullis, 1975).

On the other hand, the elongation or shape of the susceptibility ellipsoid does change progressively with increasing cleavage development. Fig-

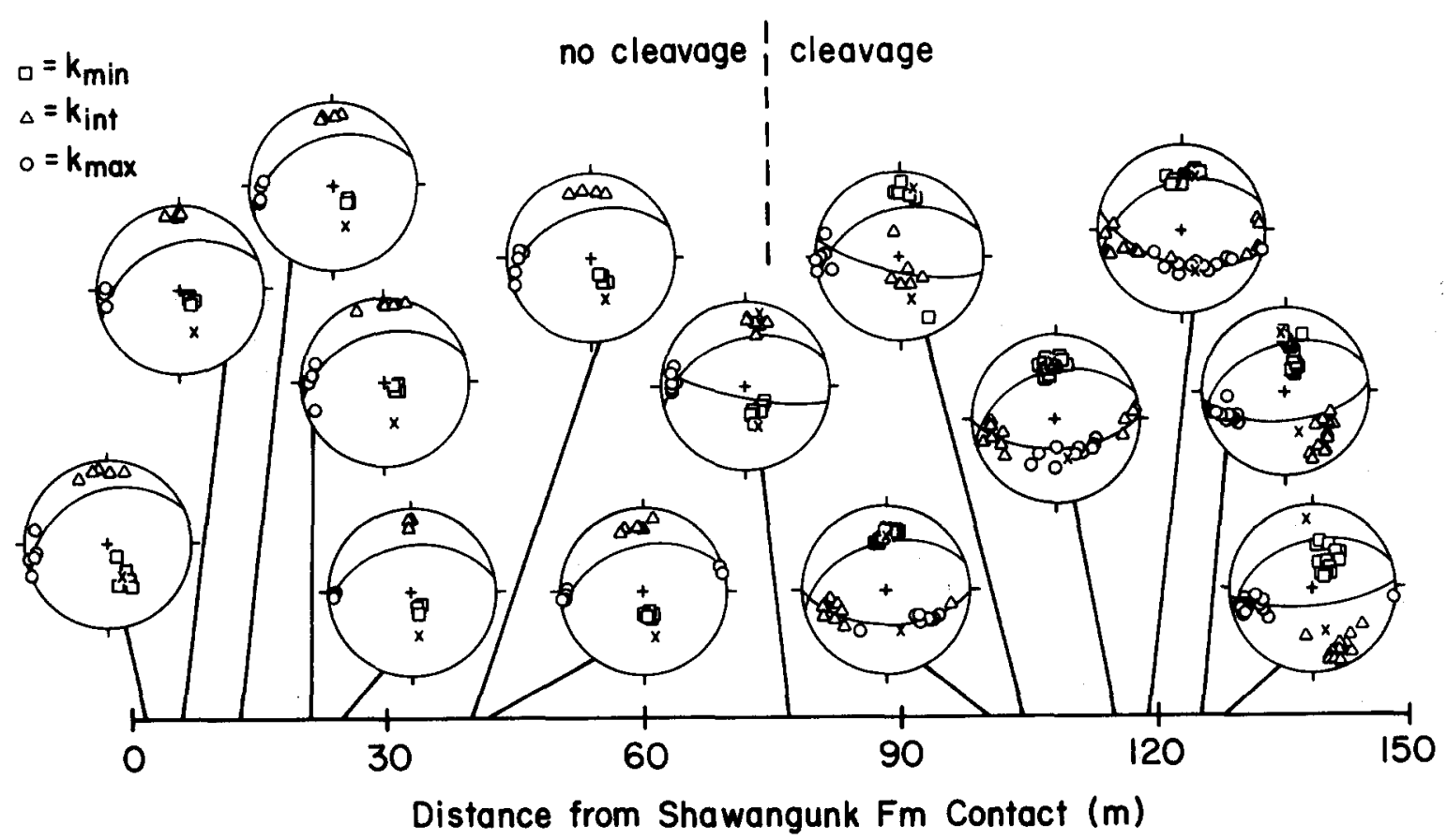

Fig. 2. Equal-area, lower-hemisphere projections of the principal susceptibility axes for each sample in this study. Bedding planes (north dipping) are shown for the uncleaved samples. Both bedding and cleavage planes (south dipping) are indicated for the cleaved samples. The horizontal scale is the distance from the contact between the Martinsburg Formation and the overlying Shawangunk Formation. Cleavage develops with increasing distance from the contact. The dashed line represents the location in which cleavage is first observed in the field. Cleavage is fully developed $120 \mathrm{~m}$ beyond the Shawangunk Formation contact. 


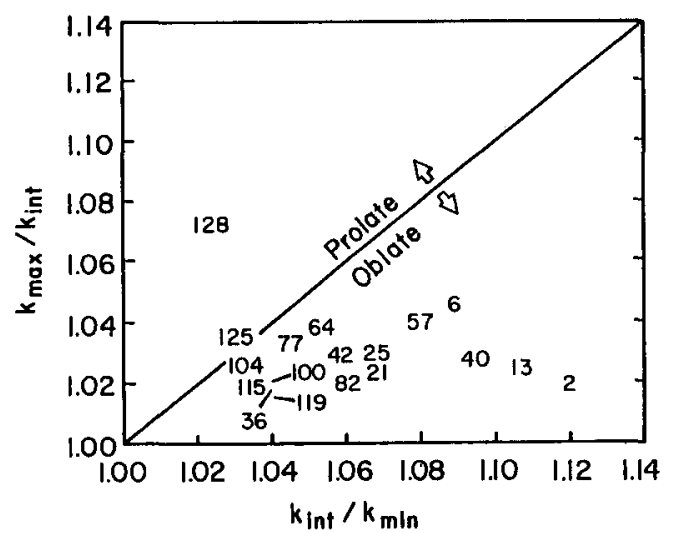

Fig. 3. Flinn diagram that shows the shape of the AMS ellipsoid. Results that fall in the oblate field indicate a magnetic foliation; results in the prolate field indicate a magnetic lineation. The distance of an individual sample from the Martinsburg-Shawangunk contact is used as a marker for that sample in this plot; increasing distance roughly equals increasing cleavage development. These results display a trend from oblate-to-prolate AMS ellipsoid shapes with increasing distance from the contact. Uncleaved samples (2-42 $\mathrm{m}$ ) group in the oblate field; samples with cleavage (77-115 m) cluster near the oblate-prolate boundary $(k=1)$, and continue the trend observed in the uncleaved samples. Fully cleaved samples (125 and $128 \mathrm{~m}$ ) lie in the prolate field.

ure 3 is a Flinn diagram that represents the susceptibility ellipsoid as a plot of the ratios of maximum/intermediate vs. intermediate/minimum susceptibility axes. The uncleaved samples display a susceptibility ellipsoid with a uniaxial-oblate shape, which indicates that the maximum and intermediate axes are of near-equal magnitudes. As the cleavage becomes fully developed, the AMS ellipsoid shape shifts into the prolate field. This pattern appears to reflect progression of strain in this shale-to-slate transition; we may then calculate apparent strain ratios from the AMS data, based on the equations of Rathore (1979) and Hrouda (1987)

$$
\begin{aligned}
\left(k_{\max } / k_{\mathrm{int}}\right) & =(X / Y)^{a} \text { solve for } X / Y:(X / Y) \\
& =\left(k_{\max } / k_{\mathrm{int}}\right)^{1 / a} \\
\left(k_{\mathrm{int}} / k_{\min }\right) & =(Y / Z)^{a} \text { solve for } Y / Z:(Y / Z) \\
& =\left(k_{\mathrm{int}} / k_{\min }\right)^{1 / a} \\
\left(k_{\max } / k_{\min }\right) & =(X / Z)^{a} \text { solve for } X / Z:(X / Z) \\
& =\left(k_{\max } / k_{\min }\right)^{1 / a}
\end{aligned}
$$

where $X \geq Y \geq Z$ are the principal strain axes and $k_{\max } \geq k_{\text {int }} \geq k_{\min }$ are the principal susceptibilities. The value of the exponent $a$ is empirical, and is suggested to be dependent upon lithology. Hrouda (1987) listed a value of $a=0.05$ for slates in general; we have used this value in our apparent-strain calculations. Table 1 lists the magnitudes of the principal susceptibility axes and the calculated apparent-strain values. Following the results in Wintsch and Kvale (1989), who reported that no volume loss occurred with cleavage formation in these rocks, the apparent strain axes $X \geq Y$ $\geq Z$ were calculated using a constant-volume model. These calculations show a clear progression in apparent strain values with developing cleavage; notably a decrease in the magnitude of the $Y$ axis and an increase in the $Z$ axis. The apparent strain values range from $2.79: 1.87: 0.19$ for shale (site Om8) to $2.92: 0.82: 0.42$ for slate (site Om32). At this point we wish to note, however, that we question the geologic relevance of the AMS-based apparent strain values in these rocks, for reasons that are discussed below.

\section{Discussion}

Studies of AMS and rock fabric (e.g. Borradaile, 1988) show that the minimum AMS axis generally lies perpendicular to the dominant planar rock fabric, such as bedding or cleavage (Fig. 4). Our comparison between AMS and rock fabric variations in the Martinsburg Formation, however, does not agree with these observations. Characteristic 'no-cleavage' fabrics from the Martinsburg Formation can be seen in the left half of Fig. 2. The minimum AMS axis is generally $20^{\circ}$ away from the pole to bedding. Cleaved samples, on the other hand, display an AMS fabric that appears to be in better agreement with the predicted fabric. Most samples taken from the interval in which the cleavage is developed yield an AMS fabric in which the minimum axis corresponds with the pole to cleavage. There are notable discrepancies, however. The site in which incipient cleavage is initially observed in the field (site Om24) continues to display an AMS fabric with the minimum axis at a high angle to the bedding plane 
TABLE 1

Principal susceptibility axes and calculated apparent strains

\begin{tabular}{|c|c|c|c|c|c|c|c|c|c|c|c|c|}
\hline \multirow[t]{2}{*}{ Site $^{a}$} & \multirow[t]{2}{*}{$N^{\mathrm{c}}$} & \multirow[t]{2}{*}{ Dist $^{b}$} & \multicolumn{3}{|c|}{$\begin{array}{l}\text { Susceptibility axes } \\
\left(1 \times 10^{-4} \text { SI units) }\right.\end{array}$} & \multirow[t]{2}{*}{$L^{e}$} & \multirow[t]{2}{*}{$F^{f}$} & \multicolumn{2}{|c|}{$\begin{array}{l}\text { Apparent } \\
\text { strain ratios }\end{array}$} & \multicolumn{3}{|c|}{$\begin{array}{l}\text { Apparent } \\
\text { strain axes h }\end{array}$} \\
\hline & & & $\overline{k_{\max }}$ & $k_{\text {int }}$ & $\overline{k_{\min }}$ & & & $\overline{X / Y}$ & $\overline{Y / Z}$ & $\bar{X}$ & $Y$ & $Z$ \\
\hline Om8 & 6 & 2 & 2.31 & 2.26 & 2.01 & 1.02 & 1.12 & 1.51 & 9.77 & 2.82 & 1.86 & 0.19 \\
\hline Om10 & 6 & 6 & 3.80 & 3.64 & 3.34 & 1.05 & 1.09 & 2.48 & 5.34 & 3.20 & 1.29 & 0.24 \\
\hline Om11 & 6 & 13 & 3.27 & 3.19 & 2.88 & 1.03 & 1.1 .1 & 1.65 & 7.53 & 2.73 & 1.66 & 0.22 \\
\hline Om14 & 6 & 21 & 2.81 & 2.75 & 2.57 & 1.02 & 1.07 & 1.59 & 3.88 & 2.14 & 1.35 & 0.35 \\
\hline Om17 & 6 & 25 & 3.11 & 3.02 & 2.83 & 1.03 & 1.07 & 1.82 & 3.74 & 2.31 & 1.27 & 0.34 \\
\hline $\mathbf{L A}$ & 6 & 36 & 2.43 & 2.38 & 2.29 & 1.02 & 1.04 & 1.48 & 2.25 & 1.70 & 1.15 & 0.51 \\
\hline Om20 & 8 & 40 & 3.75 & 3.64 & 3.33 & 1.03 & 1.10 & 1.73 & 6.25 & 2.65 & 1.53 & 0.25 \\
\hline $\mathrm{Om} 21$ & 6 & 42 & 3.17 & 3.09 & 2.91 & 1.03 & 1.06 & 1.74 & 3.33 & 2.16 & 1.24 & 0.37 \\
\hline L5 & 6 & 57 & 3.42 & 3.29 & 3.06 & 1.04 & 1.08 & 2.17 & 4.26 & 2.72 & 1.25 & 0.29 \\
\hline L6 & 6 & 64 & 3.60 & 3.47 & 3.29 & 1.04 & 1.05 & 2.09 & 2.90 & 2.33 & 1.12 & 0.38 \\
\hline Om24 & 6 & 77 & 3.57 & 3.45 & 3.29 & 1.03 & 1.05 & 1.98 & 2.68 & 2.19 & 1.11 & 0.41 \\
\hline L7 & 6 & 82 & 2.54 & 2.48 & 2.35 & 1.02 & 1.06 & 1.61 & 2.94 & 1.97 & 1.22 & 0.42 \\
\hline $\operatorname{Om} 27^{i}$ & 13 & 100 & 2.43 & 2.39 & 2.30 & 1.02 & 1.04 & 1.39 & 2.07 & 1.59 & 1.14 & 0.55 \\
\hline Om28 & 6 & 104 & 2.78 & 2.71 & 2.62 & 1.03 & 1.03 & 1.70 & 1.90 & 1.76 & 1.04 & 0.55 \\
\hline Om2 $29^{i}$ & 14 & 115 & 2.63 & 2.59 & 2.52 & 1.01 & 1.03 & 1.27 & 1.83 & 1.44 & 1.13 & 0.62 \\
\hline $\mathrm{Om} 30^{\mathrm{i}}$ & 11 & 119 & 2.46 & 2.44 & 2.34 & 1.01 & 1.04 & 1.23 & 2.27 & 1.51 & 1.23 & 0.54 \\
\hline Om31 & 12 & 125 & 3.22 & 3.12 & 3.02 & 1.03 & 1.03 & 1.86 & 1.87 & 1.86 & 1.00 & 0.54 \\
\hline Om32 & 13 & 128 & 2.72 & 2.55 & 2.47 & 1.07 & 1.03 & 3.57 & 1.95 & 2.92 & 0.82 & 0.42 \\
\hline
\end{tabular}

L4-L7 are results from an unpublished pilot study.

b Distance of a sample from the Martinsburg-Shawangunk contact in meters.

c Number of determinations of the susceptibility ellipsoid, each determination is the average of four measurements.

d $k_{\max }>k_{\text {int }}>k_{\text {min }}$ are the principal susceptibility axes.

- Magnetic lineation $\left(k_{\max } / k_{\text {int }}\right)$.

f Magnetic foliation $\left(k_{\mathrm{int}} / k_{\min }\right)$.

Strain ratios are derived from equations in Hrouda (1987), with $a=0.05$.

${ }^{\text {h }}$ Strain ellipsoid axes $(X \geq Y \geq Z)$ were calculated using a constant-volume model in which $X \times Y \times Z=1$.

i Samples with a sandy lithology.

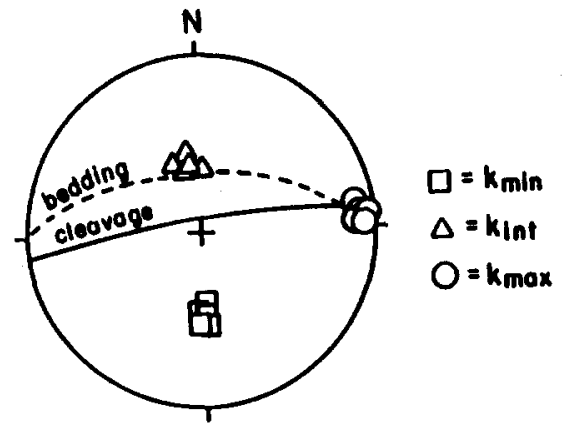

Fig. 4. Typical orientations of the principal susceptibility axes. The minimum axis is expectod to be perpendicular to a planar rock fabric, such a bedding in this example. The maximum axis is commonly found at the bedding-cleavage intersection (from Borradaile, 1988).
(Fig. 2, at $77 \mathrm{~m}$ ). Furthermore, well-cleaved samples (sites Om31 and Om32) display AMS fabrics in which the minimum axis trends towards an orientation $20^{\circ}$ away from the pole to cleavage (Fig. 2, at $128 \mathrm{~m}$ ). These discrepancies bear directly on the ability of AMS to represent rock fabrics and strain, and can be explained by the behavior of chlorite in these rocks.

\subsection{AMS and chlorite}

A comparison of AMS patterns with X-ray diffraction results from Holeywell and Tullis (1975) provides an interpretation of the variations observed in the AMS data. Figure 5 shows the 


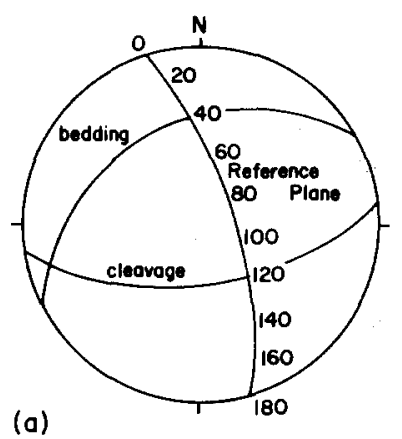

(b)

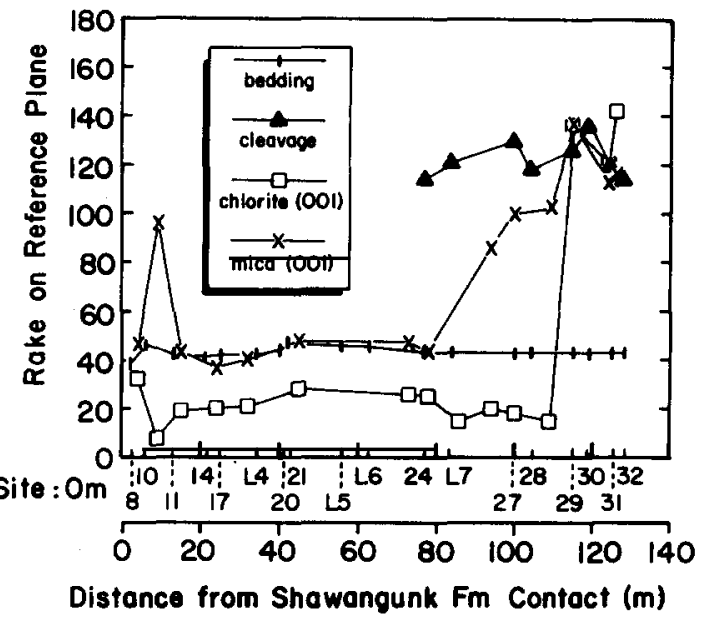

Fig. 5. Orientations of bedding, cleavage, chlorite and mica basal planes. (a) Reference plane against which orientation data are plotted. The pole to the reference plane is the bedding-cleavage intersection. Orientations are expressed as rakes on this reference plane; as shown here, bedding has a rake of $40^{\circ}$ and cleavage a rake of $120^{\circ}$. (b) Plot of bedding, cleavage, chlorite and mica basal plane orientation versus distance from the Martinsburg-Shawangunk contact. The vertical axis is the rake on the reference plane; the horizontal axis is the distance from the Martinsburg-Shawangunk contact. Site locations are indicated. Two orientations of chlorite (001) planes are observed; (i) with a rake $20^{\circ}$ from the bedding plane and (ii) with a rake approximately parallel to cleavage. No intermediate orientations were found. Mica (001) orientations are parallel to bedding in uncleaved samples and parallel to cleavage in well-cleaved samples. Intermediate orientations of mica (001) are observed with developing cleavage. (Chlorite and mica crystallographic data are from Holeywell and Tullis, 1975.)

crystallographic-preferred orientation of chlorite and mica (001) planes, derived from great-circle $\mathrm{X}$-ray scans, expressed as a rake on a reference plane perpendicular to both bedding and cleavage. Bedding and cleavage orientations are also plotted. The horizontal axis indicates the distance from the contact with the Shawangunk Formation.

Both Holeywell and Tullis (1975), and Lee et al. (1986) report a gradual increase in the number of chlorite and mica grains oriented parallel to cleavage over the interval in which cleavage is developed. Orientation of mica grains progresses from parallel-to-bedding to parallel-to-cleavage, with intermediate orientations observed in the interval in which cleavage is developed (Fig. 5b). Orientations of chlorite exhibit two populations: (i) the 'no-cleavage' population, with an (001) orientation at an angle of $20^{\circ}$ to bedding as found in the interval from 0 to $110 \mathrm{~m}$, (ii) the 'cleavage' population, with an (001) orientation parallel to the cleavage plane, as found in the interval from 115 to $130 \mathrm{~m}$ (Fig. 5b). No chlorite (001) orientation fabrics intermediate to those two patterns are present, in contrast to mica. The lack of intermediate orientations and textural relationships are cited by Holeywell and Tullis (1975) and Lee et al. (1986) as evidence that chlorite reorients entirely via pressure solution and new growth with

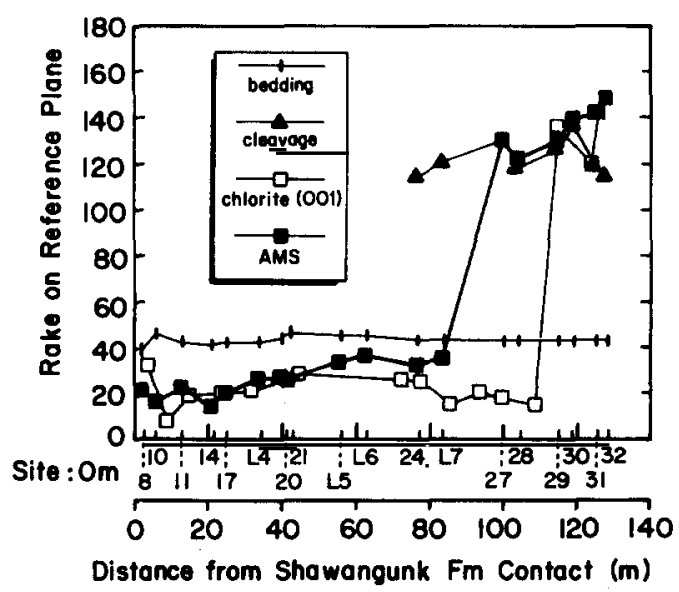

Fig. 6. Orientation of AMS axes compared with chlorite (001) orientations. The axes of this graph are the same as in Fig. 5b. For comparison with chlorite, the plane containing the intermediate and maximum AMS axes was plotted on the reference plane. 
the formation of slaty cleavage in the Martinsburg Formation.

Chlorite is a paramagnetic phyllosilicate that, when subjected to a magnetic field, yields a minimum susceptibility axis perpendicular to the (001) plane (Borradaile et al., 1987). Consequently, the intermediate and maximum susceptibility axes lie in the basal plane. For comparison with chlorite orientations, we have plotted the plane containing the intermediate and maximum susceptibility axes as a rake on the reference plane in a manner similar to that for the chlorite basal planes (Fig. 6). Close examination of Fig. 6 shows that both the uncleaved and the cleaved samples exhibit AMS patterns that follow the orientation of chlorite. Like chlorite, AMS orientations are $20^{\circ}$ away from the orientation of bedding in uncleaved samples, and are approximately parallel to cleavage in well-cleaved samples. Moreover, no AMS orientations intermediate to these orientations are observed. Additionally, the relative magnitudes of the principal susceptibility axes (Table 1) closely match the susceptibility values of chlorite listed in Borradaile et al. (1987). These combined observations show that AMS is controlled by chlorite in these samples, and provides an explanation for the discrepancy between the orientations of rock fabrics and the AMS axes. The control of AMS by chlorite in these rocks corroborates previous results (e.g. Borradaile et al., 1986) that suggest that paramagnetic matrix minerals may dominate AMS measurements in slates.

The agreement between chlorite and AMS orientations is not perfect, however, as the AMS orientation becomes parallel to cleavage closer to the Martinsburg-Shawangunk contact than does the chlorite orientation. The shift in the dominant chlorite (001) orientation (Fig. 6) occurs $115 \mathrm{~m}$ from the Shawangunk Formation contact. On the other hand, the abrupt change in orientation of the AMS fabric occurs at a point $\sim 90 \mathrm{~m}$ from the Shawangunk Formation contact, roughly coinciding with the first appearance of cleavage in the field rather than the change in dominant chlorite (001) orientation as measured by texture goniometry. This observation may simply reflect the differing sensitivities of AMS and X-ray methods to changes in bulk crystallographic orientation.

\section{2. $A M S$ and strain}

Various relationships between strain and AMS have been proposed (e.g. Singh et al., 1975; Hrouda, 1976, 1980; Kligfield et al., 1977; Rathore, 1979; Rochette and Vialon, 1984). For example, Rathore (1979, 1988) and Hrouda (1987) present results correlating the development of cleavage, strain and AMS in slates. Rathore (1979) related the magnitude of the principal susceptibility axes to March strains in Cambrian slates of North Wales; the equations used previously were derived from this work (Hrouda, 1987). As discussed in the previous section, AMS patterns are controlled by the orientation of chlorite in the Martinsburg Formation samples, and thus, the behavior of chlorite during progressive cleavage development constrains any model relating AMS and strain in the Martinsburg slates (see also Rochette, 1987). The behavior of chlorite in the Martinsburg Formation shale-to-slate transition does not fit the critical assumptions made in Rathore (1979), which call for rigid-body rotation (March-strain model) of the susceptibility-carrier grains as cleavage is formed, and rests upon the assumption that no recrystallization of the susceptibility carriers has occurred. We conclude that if dissolution-neocrystallization of chlorite is characteristic for the formation of cleavage in slates, AMS fabrics record only the degree of pressure solution and new growth. A direct relationship between dissolutionprecipitation and strain is not known and, thus, the AMS magnitudes may not represent finite strain.

\section{Conclusions}

Comparison of AMS and chlorite fabrics in the Martinsburg Formation shale-to-slate transition shows that AMS measures the orientation of chlorite basal planes in these rocks. The abundance of paramagnetic chlorite dominates the susceptibility patterns; other magnetic phases contribute relatively little. Consequently, the ability of AMS to characterize rock fabrics is limited to rock fabrics controlled by, or which control, chlorite orientation. Because the AMS fabric follows the orienta- 
tion of chlorite, the behavior of this phyllosilicate during progressive cleavage development determines the apparent strain magnitudes deduced from AMS measurements. In the Martinsburg slates, chlorite undergoes extensive dissolution and neocrystallization; rotation during progressive cleavage development was absent. Therefore, until models correlating AMS and strain allow for dissolution and precipitation of the susceptibility carriers, the calculated 'strain' values only reflect the degree of pressure solution and new growth and do not necessarily reflect finite strain.

\section{Acknowledgements}

Research was supported by the American Chemical Society-Petroleum Research Fund (grant 20755) and the National Science Foundation (grant 86-12469). We wish to thank Beth Housen and Martha Ballard for field assistance, and Art Lombard for a preliminary study of Martinsburg samples. John Geissman, Roberto Molina, Rob van der Voo and an anonymous reviewer provided comments and suggestions. Susan Fast drafted the illustrations.

\section{References}

Anonymous, 1885. Report of the 2nd Pennsylvania Geologic Survey, Vol. D5.

Borradaile, G.J., 1987. Anisotropy of magnetic susceptibility: rock composition versus strain. Tectonophysics, 138: $327-$ 329.

Borradaile, G.J., 1988. Magnetic susceptibility, petrofabrics and strain. Tectonophysics, 156: 1-20.

Borradaile, G.J. and Alford, C., 1987. Relationship between magnetic susceptibility and strain in laboratory experiments. Tectonophysics, 133: 121-135.

Borradaile, G.J. and Alford, C., 1988. Experimental shear zones and magnetic fabrics. J. Struct. Geol., 10: 895-904.

Borradaile, G.J., Mothersill, J., Tarling, D. and Alford, C., 1986. Sources of magnetic susceptibility in a slate. Earth Planet. Sci. Lett., 76: 336-340.

Borradaile, G.J., Keeler, W., Alford, C. and Sarvas, P., 1987. Anisotropy of magnetic susceptibility of some metamorphic minerals. Phys. Earth Planet. Inter., 48: 161-166.

Cogne, J.P. and Perroud, H., 1988. Anisotropy of magnetic susceptibility as a strain gauge in the Flamanville granite. NW France. Phys. Earth Planet. Inter., 51: 264-270.
Drake, A.A. and Epstein, J.B., 1967. The Martinsburg Formation (middle and upper Ordovician) in the Delaware Valley, Pennsylvania-New Jersey, U.S. Geol. Surv. Bull. 1244-H. $16 \mathrm{pp}$.

Epstein, J.B. and Epstein, A.G., 1969. Geology of the Valley and Ridge province between Delaware Water Gap and Lehigh Gap, Pennsylvania. In: S. Subitzky (Editor), Geology of Selected Areas in New Jersey and Eastern Pennsylvania, and Guidebook of Excursions. Rutgers University Press, New Brunswick, N.J., pp. 132-205.

Goldstein, A.G. and Brown, L.L., 1988. Magnetic susceptibility anisotropy of mylonites from the Brevard Zone, North Carolina, U.S.A. Phys. Earth Planet. Inter., 51: 290-300.

Hirt, A.M., Lowrie, W., Clendenen, W.S. and Kligfield, R., 1988. The correlation of magnetic anisotropy with strain in the Chelmsford Formation of the Sudbury Basin, Ontario. Tectonophysics, 145: 177-189.

Holeywell, R.C. and Tullis, T.E., 1975. Mineral reorientation and slaty cleavage in the Martinsburg Formation, Lehigh Gap, Pennsylvania. Geol. Soc. Am. Bull., 86: 1296-1304.

Hrouda, F., 1976. The origin of cleavage in the light of magnetic anisotropy investigations. Phys. Earth Planet. Inter., 13: 132-142.

Hrouda, F., 1980. Magnetocrystalline anisotropy of rocks and massive ores: a mathematical model study and its fabric implications. J. Struct. Geol., 2: 459-462.

Hrouda, F., 1987. Mathematical model relationship between the paramagnetic anisotropy and strain in slates. Tectonophysics, 142: 323-327.

Hrouda, F., Jacko, S. and Hanak, J., 1988. Parallel magnetic fabrics in metamorphic, granitoid and sedimentary rocks of the Branisko and Cierna Hora Mountains (E. Slovakia) and their tectonometamorphic control. Phys. Earth Planet Inter., 51: 271-289.

Kligfield, R., Lowrie, W. and Dalziel, I., 1977. Magnetic susceptibility anisotropy as a strain indicator in the Sudbury Basin, Ontario. Tectonophysics, 40: 287-308.

Lee, J.H., Peacor, D.R., Lewis, D. and Wintsch, R.P., 1986. Evidence for syntectonic crystallization for the mudstone to slate transition at Lehigh Gap, Pennsylvania, U.S.A. J. Struct. Geol., 8: 767-780.

McBride, E.F., 1962. Flysch and associated beds of the Martinsburg Formation (Ordovician), central Appalachians. J. Sediment. Petrol., 32: 39-91.

Owens, W.H., 1974. Mathematical model studies on factors affecting the magnetic anisotropy of deformed rocks. Tectonophysics, 24: 115-131.

Rathore, J.S., 1979. Magnetic susceptibility anisotropy in the Cambrian Slate Belt of North Wales and correlation with strain. Tectonophysics, 53: 83-97.

Rathore, J.S., 1988. Strain to anisotropy correlations corrected for the Digico calibration error. Phys. Earth Planet. Inter., 51: $355-360$.

Rochette, P., 1987. Magnetic susceptibility of the rock matrix related to magnetic fabric studies, J. Struct. Geol., 9: 10151020. 
Rochette, P. and Vialon, P., 1984. Development of planar and linear fabrics in Dauphinois shales and slates (French Alps) studied by magnetic anisotropy and its mineralogical control. J. Struct. Geol., 6: 33-38.

Singh, J. (now Rathore, J.), Sanderson, D.J. and Tarling, D.H. 1975. The magnetic susceptibility anisotropy of deformed rocks from North Cornwall, England. Tectonophysics, 27: 141-153.

Stupavsky, M., 1984. Operating Manual for SI-2 Magnetic Susceptibility Instrument. Sapphire Instruments, 190 pp.
Wintsch, R.P., 1978. A chemical approach to the preferred orientation of mica. Geol. Soc. Am. Bull., 89: 1715-1718.

Wintsch, R.P. and Kvale, C.M. 1989. Open system, constant volume development of slaty cleavage, and strain induced reaction at Lehigh Gap, PA. Geol. Soc. Am. Abstr. Progrms, NE Section, 21 (2): 76.

Wood, D.S., Oertel, G., Singh, J. and Bennet, M.F., 1976. Strain and anisotropy in rocks, Philos. Trans. R. Soc. London, Ser. A, 283: 78-80. 